\title{
A Case Report of Prilocaine-Induced Methemoglobinemia after Liposuction Procedure
}

\author{
Birdal Yildirim, ${ }^{1}$ Ulku Karagoz, ${ }^{2}$ Ethem Acar, ${ }^{1}$ Halil Beydilli, ${ }^{1}$ Emine Nese Yeniceri, ${ }^{3}$ \\ Ozgur Tanriverdi, ${ }^{4}$ Omer Dogan Alatas, ${ }^{2}$ and Şükrü Kasap ${ }^{5}$ \\ ${ }^{1}$ Department of Emergency Medicine, Muğla Sıtkı Koçman University Medical Faculty, Orhaniye Mahallesi Haluk Ozsoy Caddesi, \\ 48000 Mugla, Turkey \\ ${ }^{2}$ Emergency Clinic, Muğla Sıtkı Koçman University Training and Investigation Hospital, Orhaniye Mahallesi Haluk Ozsoy Caddesi, \\ 48000 Mugla, Turkey \\ ${ }^{3}$ Department of Family Medicine, Muğla Sıtkı Koçman University Medical Faculty, Orhaniye Mahallesi Haluk Ozsoy Caddesi, \\ 48000 Mugla, Turkey \\ ${ }^{4}$ Department of Internal Medicine and Medical Oncology, Muğla Sıtkı Koçman University Medical Faculty, \\ Orhaniye Mahallesi Haluk Ozsoy Caddesi, 48000 Mugla, Turkey \\ ${ }^{5}$ Clinic of Plastic and Reconstructive Surgery, Muğla Sitkı Koçman University Training and Investigation Hospital, \\ Orhaniye Mahallesi Haluk Ozsoy Caddesi, 48000 Mugla, Turkey
}

Correspondence should be addressed to Emine Nese Yeniceri; neseyeniceri@mu.edu.tr

Received 28 February 2015; Accepted 11 June 2015

Academic Editor: Chih Cheng Lai

Copyright (C) 2015 Birdal Yildirim et al. This is an open access article distributed under the Creative Commons Attribution License, which permits unrestricted use, distribution, and reproduction in any medium, provided the original work is properly cited.

Prilocaine-induced methemoglobinemia is a rarely seen condition. In this paper, a case is presented with methemoglobinemia developed secondary to prilocaine use in a liposuction procedure, and the importance of this rarely seen condition is emphasized. A 20 -year-old female patient presented with complaints of prostration, lassitude, shivering, shortness of breath, and cyanosis. It was learned that the patient underwent nearly $1000 \mathrm{mg}$ prilocaine infiltration 8 hours priorly during a liposuction procedure. At admission, her blood pressure $(130 / 80 \mathrm{mmHg})$, pulse rate $(140 \mathrm{bpm})$, body temperature $\left(36^{\circ} \mathrm{C}\right)$, and respiratory rate $(40 / \mathrm{min})$ were recorded. The patient had marked acrocyanosis. The arterial blood gas methemoglobin level was measured as $40 \%$. The patient received oxygen therapy with a mask and was administered vitamin $\mathrm{C}$ in normal saline $(500 \mathrm{mg}$ tid), $\mathrm{N}$-acetylcysteine (300 mg tid), and $50 \mathrm{mg} \mathrm{10 \%} \mathrm{methylene} \mathrm{blue} \mathrm{in} \mathrm{the} \mathrm{intensive} \mathrm{care} \mathrm{unit} \mathrm{of} \mathrm{the} \mathrm{internal} \mathrm{medicine} \mathrm{department.} \mathrm{Methemoglobin} \mathrm{level} \mathrm{dropped}$ down to $2 \%$ after her treatment with methylene blue and she was clinically cured and discharged 2 days later. Emergency service physicians should remember to consider methemoglobinemia when making a differential diagnosis between dyspnea and cyanosis developing after prilocaine infiltration performed for liposuctions in the adult age group.

\section{Introduction}

Methemoglobinemia is defined as an increase in the blood methemoglobin level, and it is an important cause of cyanosis [1]. When ferrous $\left(\mathrm{Fe}^{2+}\right)$ hemoglobin oxidizes iron and transforms it into a ferric $\left(\mathrm{Fe}^{3+}\right)$ cation, methemoglobin forms. The methemoglobin level is held at low levels via the reductizing cytochrome b5 reductase enzyme (NADHmethemoglobin reductase) levels in erythrocytes [1]. Indeed, methemoglobin is not functional in contrast with oxygencarrying hemoglobin, and conditions with increased blood methemoglobin levels convey clinical importance [2]. The most important clinical symptom of methemoglobinemia is cyanosis, and it should be considered in particular in cyanotic patients with normal cardiovascular and pulmonary functions [2]. In mild cases, clinical signs and symptoms may not be observed; however, severe cases may present with cyanosis, tachypnea, hypotension, tachycardia, and confusion. Advanced cases may be fatal [2].

The pathophysiology of methemoglobinemia involves an imbalance between oxidation and reduction $[1,2]$. It may emerge as a hereditary or acquired condition [2]. The most 
important cause of acquired methemoglobinemia is exposure of healthy individuals to drugs or chemical substances [2]. Such chemicals as nitrite, nitrate, aniline, and benzene compounds and drugs like sulfonamides, dapsone, phenacetin, primaquine, and benzocaine make up the most important agents $[2,3]$. Prilocaine, an amide compound that is frequently used as a local anesthetic, can also cause methemoglobinemia [3].

Based on a literature review, cases with prilocaineinduced methemoglobinemia are frequently seen in neonatal and early pediatric ages $[4,5]$. Prilocaine-induced methemoglobinemia during liposuction is rarely seen. In this paper, in consideration of the rarity of this condition, a severe case of prilocaine-induced methemoglobinemia in a patient who underwent regional liposuction is presented.

\section{Case Presentation}

A 20-year-old female patient without any previous systemic disease applied to this emergency service with complaints of shivering, prostration, lassitude, fatigue, shortness of breath, and cyanosis of the lips. The general health state of the patient was deteriorated. An inspection of the patient revealed a tachypneic pulse and cyanotic lips. The patient's blood pressure $(130 / 80 \mathrm{~mm} / \mathrm{Hg})$, respiratory rate $(40 / \mathrm{min})$, pulse rate (rhythmic, $140 \mathrm{bpm})$, body temperature $\left(36^{\circ} \mathrm{C}\right)$, and oxygen saturation $\left(\mathrm{SpO}_{2}, 82 \%\right)$ were measured with normal pulmonary and cardiovascular examination findings. Her chest X-ray and electrocardiographic examination results were within normal limits. The whole blood cell count and blood biochemistry did not yield any abnormal results, which would explain the clinical health state and metabolic, hematological, infective, renal, and hepatic diseases of the patient. Similarly, no respiratory or cardiovascular abnormality that could account for her actual clinical health state was detected. With an arterial blood gas $\mathrm{pH}, 7.46, \mathrm{pCO}_{2}, 31.1 \mathrm{~mm} \mathrm{Hg}$, $\mathrm{pO}_{2}, 83.3 \mathrm{~mm} \mathrm{Hg}, \mathrm{HCO}_{3}, 20 \mathrm{mEq} / \mathrm{L}$, lactate, $3.6 \mathrm{mmol} / \mathrm{L}$, and methemoglobin, $40 \%$, the patient was considered to have methemoglobinemia. Despite the initiation of a saline infusion $(100 \mathrm{~mL} / \mathrm{hr})$ and oxygen delivery with a mask at a rate of $10 \mathrm{~mL} / \mathrm{kg}$, her cyanosis persisted, and the patient was monitored in the intensive care unit of the department of internal medicine.

When the patient was stabilized, it was learned from her detailed anamnesis that she had undergone liposuction from her medial aspects of both femoral regions eight hours prior to the onset of her complaints. A total of $1000 \mathrm{mg}$ prilocaine was used during the liposuction procedure, and $100-200 \mathrm{mg}$ of the drug might be retained within the procedural site. Her treatment was continued with a vitamin C $(3 \times 500 \mathrm{mg})$ infusion in normal saline, $\mathrm{N}$-acetylcysteine $(3 \times 300 \mathrm{mg})$, and $50 \mathrm{mg} \mathrm{10 \%} \mathrm{methylene} \mathrm{blue.} \mathrm{Her} \mathrm{methemoglobin} \mathrm{level}$ dropped to $2 \%$, and her clinical findings improved. She was discharged two days after her admission into the intensive care unit.

\section{Discussion}

In this case report, in consideration of its rarity, an adult patient who consulted emergency services with clinical manifestations of severe methemoglobinemia which developed after the application of prilocaine during a regional liposuction is presented.

Methemoglobinemia can develop under the influence of hereditary and acquired factors [2]. Many drugs and chemical substances are known to induce acquired methemoglobinemia. The local anesthetic prilocaine is among these methemoglobinemia-inducing drugs $[2,6]$.

As a local anesthetic drug, the therapeutic dose of prilocaine has been reported as $1-2 \mathrm{mg} / \mathrm{kg}$, and, in cases with methemoglobinemia emerging at its therapeutic doses, cyanosis cannot be observed [7]. The maximum safe dose of prilocaine is $8 \mathrm{mg} / \mathrm{kg}$, while the daily maximum dose is $600 \mathrm{mg}$ [8]. However, increasingly higher doses have been used during liposuction procedures [9]. It has been reported that, despite higher doses of prilocaine being used in the tumescent liposuction method, the risk of methemoglobinemia is lower, which indicates the safety of this liposuction method [9]. In a study of 25 cases in which patients had undergone liposuction with this technique, methemoglobinemia had not developed [10]. In the tumescent infiltrative liposuction technique, a substantial amount of local anesthetic infiltrated subcutaneously is removed from the body via the aspiration method [11]. The biological halflife of prilocaine is 55 minutes, and the time required for the development of methemoglobinemia is $20-60$ minutes [8]. In this case, $1000 \mathrm{mg}$ prilocaine was infiltrated and nearly 800 $900 \mathrm{mg}$ of the drug was aspirated. A total of $100-200 \mathrm{mg}$ was aspirated by the body cavities. It is believed that, despite the use of lower than toxic doses of prilocaine, the prolongation of the procedure for 6-8 hours induced the development of methemoglobinemia.

Methemoglobinemia should be taken into consideration in the differential diagnosis of patients with normal circulatory and respiratory system findings who consult with cyanosis [2]. Under physiological conditions, methemoglobin constitutes $1 \%$ of $\mathrm{Hb}$ and does not exceed more than $2-3 \%$ of $\mathrm{Hb}$ [1]. However, a derangement of the balance between oxidation and reduction can increase the prilocaine concentration above physiologic levels [2]. Exposure to some oxidant substances can induce methemoglobinemia even in healthy individuals. However, in healthy individuals, the increased methemoglobin concentration is lowered to normal levels by means of the cytochrome b5 reductase enzyme found in red blood cells $[1,3,6]$. In some cases, the compensation mechanism does not function properly, and increasing levels of methemoglobin cannot transport $\mathrm{O}_{2}$, which shifts the hemoglobin-oxygen dissociation curve to the left, thereby complicating the delivery of oxygen to the tissues $[1,3,6]$.

Mild cases can be asymptomatic, but, in severe cases, cyanosis, tachypnea, tachycardia, hypotension, confusion, or even death may be observed [4]. In cases with methemoglobinemia, varying degrees of cyanosis can be detected which are associated with blood methemoglobin levels $[3,6]$. 
When blood methemoglobin levels exceed 10\%, peripheral cyanosis becomes apparent, and, in cases with methemoglobin levels of $\geq 35 \%$, tissue hypoxia and diffuse cyanosis are seen. When methemoglobin levels approach $70 \%$, the patient enters a coma and if untreated may die $[1,3,6]$.

The patient who received prilocaine during a regional liposuction had a methemoglobin level of $40 \%$ at admission and presented clinically with fatigue, shivering, diffuse perioral and peripheral cyanosis, tachypnea, and tachycardia. The methemoglobinemia level of this patient and the clinical findings were compatible with the literature findings.

During the first months of life, a transient deficiency of cytochrome b5 reductase enzyme activity predisposes newborns and infants to methemoglobinemia [1]. However, since during the first 3 months of life the cytochrome b5 reductase activity is $50 \%$ of the level found in adults, even with therapeutic doses of prilocaine, methemoglobinemia can develop [7]. Therefore, many cases with methemoglobinemia can be found in the literature which have been encountered during surgical procedures performed on newborns with local anesthesia $[4,5,12]$.

The first measure to be applied after the development of methemoglobinemia following an exposure to a chemical agent or drug is the prevention of exposure to this substance. Patients with levels of methemoglobin over 20\% can improve spontaneously, and it must be remembered that, above this level, clinical manifestations can worsen [13]. As treatment alternatives, methylene blue, ascorbic acid, and riboflavin are recommended for these patients. The mortality risk is higher in cases with methemoglobin levels of $\geq 70 \%$; hyperbaric oxygen therapy is recommended for these patients [14]. However, methylene blue is the first treatment alternative for all cases. Animal and in vitro human experiments have demonstrated that ascorbic acid decreases the methemoglobin levels through a nonenzymatic process [14]. Additionally, in previous in vitro studies, Nacetylcysteine has been reported to be an important alternative approach in the treatment of nitric oxide related methemoglobinemia $[15,16]$. However, $\mathrm{N}$-acetylcysteine was shown to have no effect on human volunteers in a study conducted by Tanen et al. [17]. Similarly, in a study carried out by Dötsch et al. [18], effects of treatment with methylene blue, riboflavin, and $\mathrm{N}$-acetylcysteine were compared in patients with methemoglobinemia but $\mathrm{N}$-acetylcysteine and low-dose riboflavin were found not to change methemoglobin formation. Therefore, $\mathrm{N}$-acetylcysteine has not yet found a place in clinical practice as treatment for methemoglobinemia [18, 19]. However, it should be kept in mind that methylene blue is contraindicated in patients with glucose-6-phosphate dehydrogenase deficiency whose methemoglobinemia, paradoxically, may worsen [19].

Since this patient's level of methemoglobinemia was $40 \%$, systemic toxic symptoms were in the foreground, and intravenous infusion of methylene blue at a rate of $1-2 \mathrm{mg} / \mathrm{kg} / 5 \mathrm{~min}$ was initiated when the antioxidant therapy failed to elicit an adequate response.

In conclusion, methemoglobinemia should be considered in patients with incompatible oxygen saturation and $\mathrm{pO}_{2}$ results who developed cyanosis following minimally invasive surgical interventions. With perfect history taking and appropriate differential diagnoses, methemoglobinemia treatment can be improved without giving rise to the deterioration of the clinical picture.

\section{Conflict of Interests}

The authors declare that there is no conflict of interests regarding the publication of this paper.

\section{References}

[1] G. R. Honig, "Hemoglobin disorder," in Nelson Textbook of Pediatrics, R. E. Behrman, R. M. Kleigman, and H. B. Jenson, Eds., pp. 1478-1488, Saunders, Philadelphia, Pa, USA, 2000.

[2] E. Türkmen, G. Kocabay, A. S. Yavuz et al., "A case of methemoglobinemia induced by the administration of prilocaine prior to an epilation procedure," Journal of 1st Faculty of Medicine, vol. 68, pp. 19-21, 2005.

[3] M. D. Coleman and N. A. Coleman, "Drug induced methemoglobinemia," Drug Safety, vol. 14, no. 6, pp. 394-405, 1996.

[4] D. Benini, L. Vivo, and V. Fanos, "Acquired methemoglobinemia: a case report," La Pediatria Medica e Chirurgica, vol. 20, no. 6, pp. 411-413, 1998.

[5] B. T. Çelik and N. Çelik, "Methemoglobinemia due to prilocaine: a case report," Van Tip Dergisi, vol. 21, no. 1, pp. 44-45, 2014.

[6] D. Svecová and D. Böhmer, "Congenital and acquired methemoglobinemia and its therapy," Casopis Lékaru Ceských, vol. 137, pp. 168-170, 1998.

[7] S. G. Aygencel, E. Akinci, and G. Pamukcu, "Prilocaine induced methemoglobinemia," Saudi Medical Journal, vol. 27, no. 1, pp. 111-113, 2006.

[8] E. Lunenfeld and G. C. Kane, "Methemoglobinemia: sudden dyspnea and oxyhemoglobin desaturation after esophagoduodenoscopy," Respiratory Care, vol. 49, no. 8, pp. 940-942, 2004.

[9] W. Hanke, S. E. Cox, N. Kuznets, and W. P. Coleman III, "Tumescent liposuction report performance measurement initiative: national survey results," Dermatologic Surgery, vol. 30, no. 7, pp. 967-978, 2004.

[10] N. Lindenblatt, L. Belusa, B. Tiefenbach, W. Schareck, and R. R. Olbrisch, "Prilocaine plasma levels and methemoglobinemia in patients undergoing tumescent liposuction involving less than 2,000 ml," Aesthetic Plastic Surgery, vol. 28, no. 6, pp. 435-440, 2004.

[11] O. Lapid, "Syringe-delivered tumescent anesthesia made easier," Aesthetic Plastic Surgery, vol. 35, no. 4, pp. 601-602, 2011.

[12] T. Yılmaz, S. Ayşe, G. Serdal, and Ö. Ünsal, "Sünnet öncesi uygulanan lokal prilokaine bağlı methemoglobinemi olgusu," Dicle Tip Dergisi, vol. 3, no. 1, pp. 53-55, 2009.

[13] Y. F. Su, L. H. Lu, T. H. Hsu, S. L. Chang, and R. T. Lin, "Successful treatment of methemoglobinemia in an elderly couple with severe cyanosis: two case reports," Journal of Medical Case Reports, vol. 6, article 290, 2012.

[14] R. B. Abu-Laban, P. J. Zed, R. A. Purssell, and K. G. Evans, "Severe methemoglobinemia from topical anesthetic spray: case report, discussion and qualitative systematic review," Canadian Journal of Emergency Medicine, vol. 3, no. 1, pp. 51-56, 2001.

[15] R. O. Wright, B. Magnani, M. W. Shannon, and A. D. Woolf, "N-acetylcysteine reduces methemoglobin in vitro," Annals of Emergency Medicine, vol. 28, no. 5, pp. 499-503, 1996. 
[16] R. O. Wright, A. D. Woolf, M. W. Shannon, and B. Magnani, "N-acetylcysteine reduces methemoglobin in an in-vitro model of glucose-6-phosphate dehydrogenase deficiency," Academic Emergency Medicine, vol. 5, no. 3, pp. 225-229, 1998.

[17] D. A. Tanen, F. LoVecchio, and S. C. Curry, "Failure of intravenous $\mathrm{N}$-acetylcysteine to reduce methemoglobin produced by sodium nitrite in human volunteers: a randomized controlled trial," Annals of Emergency Medicine, vol. 35, no. 4, pp. 369-373, 2000.

[18] J. Dötsch, S. Demirakça, M. Kratz, R. Repp, I. Knerr, and W. Rascher, "Comparison of methylene blue, riboflavin, and $\mathrm{N}$-acetylcysteine for the reduction of nitric oxide-induced methemoglobinemia," Critical Care Medicine, vol. 28, no. 4, pp. 958-961, 2000.

[19] S. M. Bradberry, "Occupational methaemoglobinaemia: mechanisms of production, features, diagnosis and management including the use of methylene blue," Toxicological Reviews, vol. 22, no. 1, pp. 13-27, 2003. 


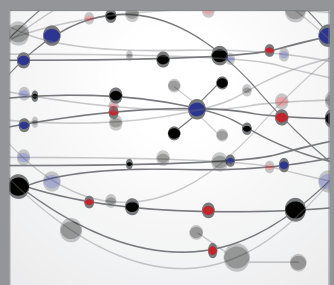

The Scientific World Journal
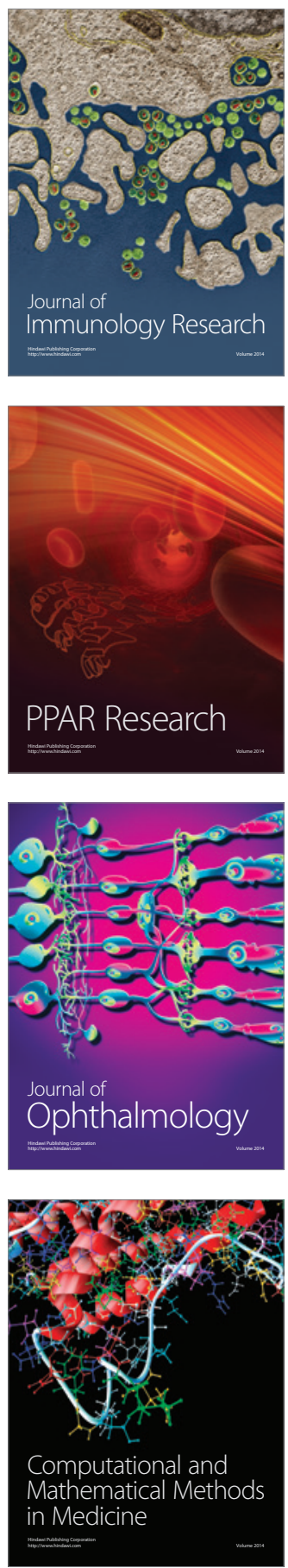

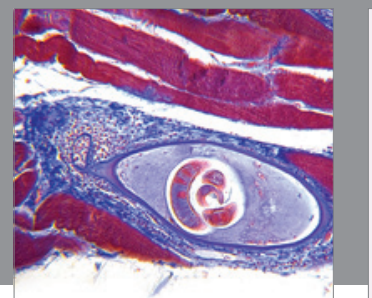

Gastroenterology

Research and Practice
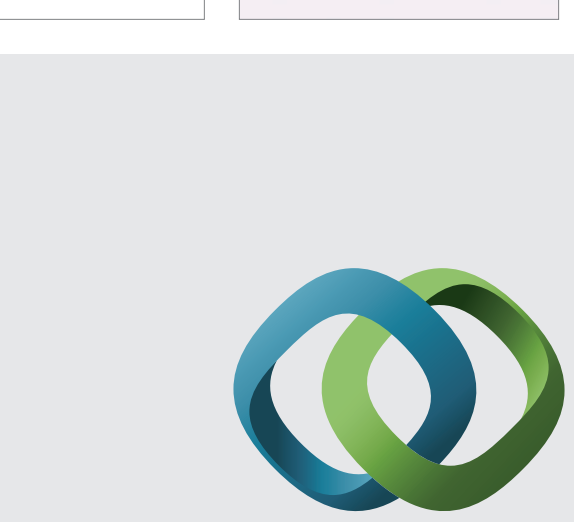

\section{Hindawi}

Submit your manuscripts at

http://www.hindawi.com
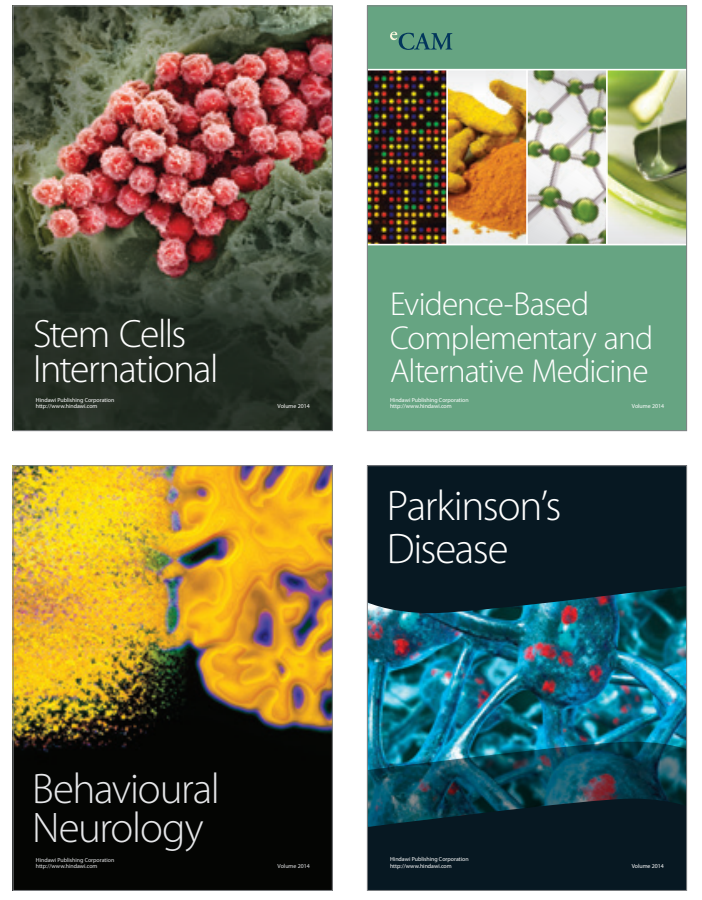
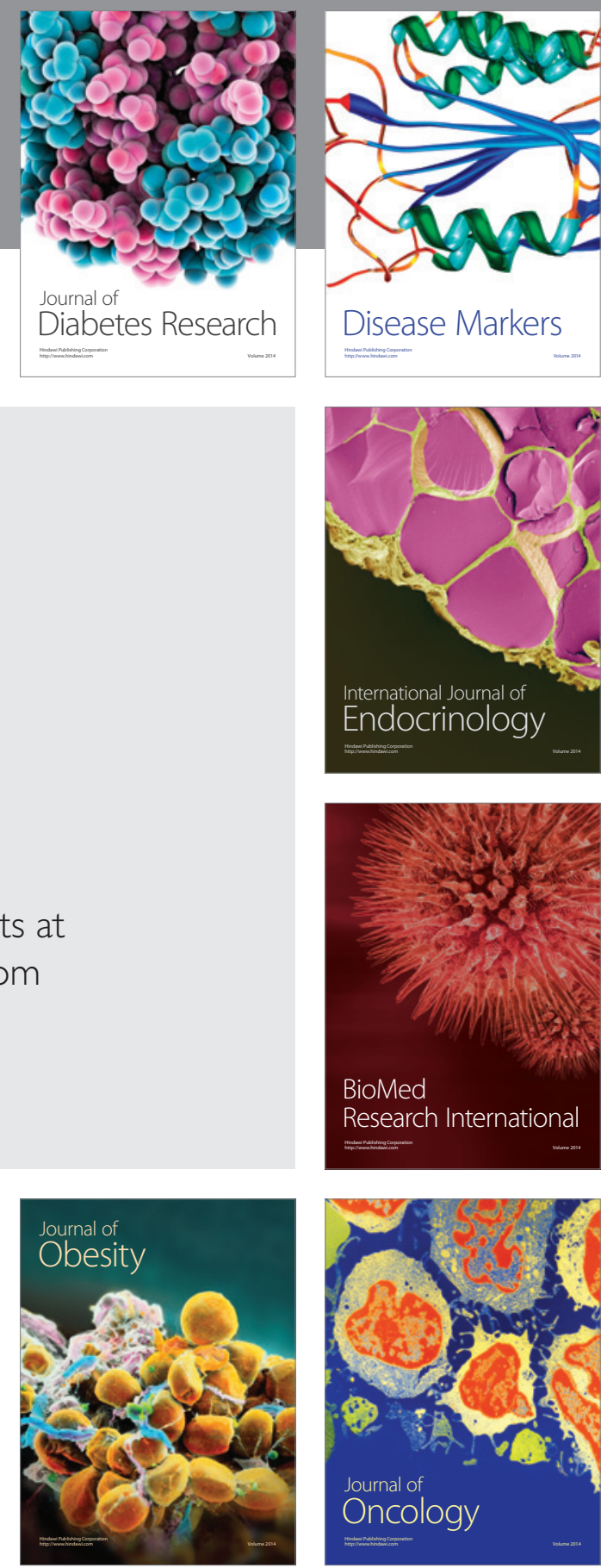

Disease Markers
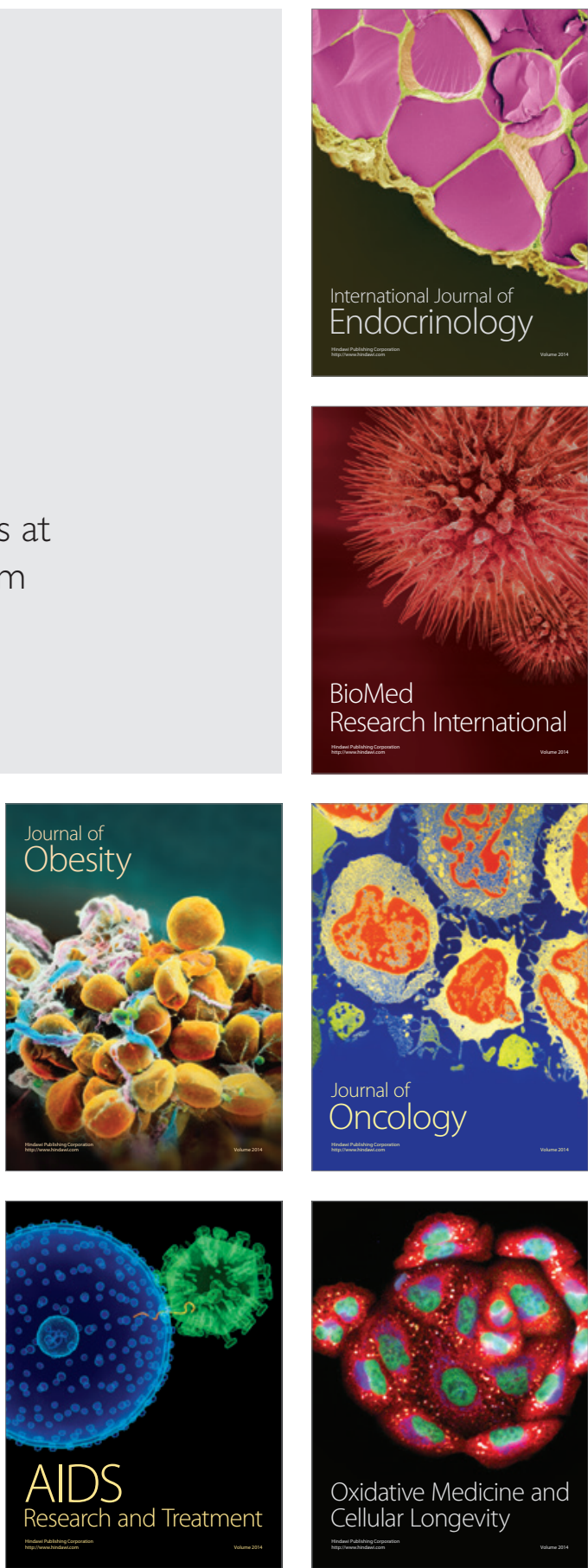